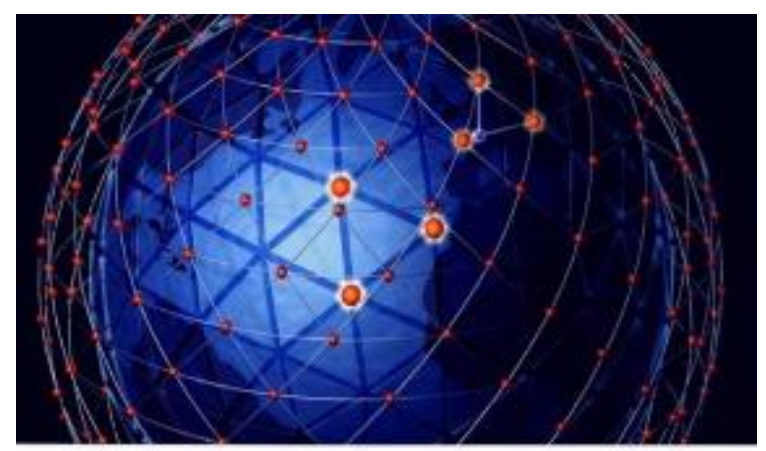

\title{
Em Sociedade
}

\section{A Política sobre Drogas para as Escolas Públicas do Distrito Federal: uma lei para os ingleses?}

\section{Drugs Politcs to Public Schools at Federal District: a law to english?}

Msc. Maraisa Bezerra Lessa ${ }^{1}$ Msc. Mauro Gleisson de Castro Evangelista ${ }^{2}$

\footnotetext{
${ }^{1}$ Doutoranda do Programa de Pós-graduação em Política Social da UnB e Professora do IFG Águas Lindas.

${ }^{2}$ Doutorando do Programa de Pós-graduação em Educação da UnB e Professor da SEDF
} 


\section{Resumo}

O artigo tem como objetivo relatar o processo de implementação da Política sobre Drogas da Secretaria de Educação do Distrito Federal, que orienta as Escolas públicas do Distrito Federal a desenvolverem ações de enfrentamento às drogas, na contramão do senso comum e em sintonia com a Política Nacional sobre Drogas vigente até 2018. Pretende descrever as ações previstas, realizadas, bem como os obstáculos para a sua efetiva implementação. Trata-se de um relato de experiências desenvolvido por meio da metodologia da observação participante, no período de dezembro de 2011 a abril de 2014. O trabalho conclui que, apesar dos esforços da equipe gestora, o referido documento orientador tornou-se letra morta, apenas mais uma lei para os ingleses, porém, de suma importância para repensarmos os caminhos trilhados pela Escola frente ao fenômeno das drogas.

\section{Abstract}

This article aims to report the implementation process the drugs politics in Stadual Secretariat of Education of the Federal District (Brazil), which guides public schools to develop drug control actions, against common sense and in line with the National Drug Policy in force until 2018. It intends to describe the planned actions carried out, as well as the obstacles to their effective implementation. This is an experience report developed through participant observation methodology, in the period from December 2011 to April 2014. The paper concludes that, despite the efforts of the management team, this guiding document has become a dead letter, just another law for the English see, but of great importance to rethink the paths taken by the School in the face of the drug phenomenon. 


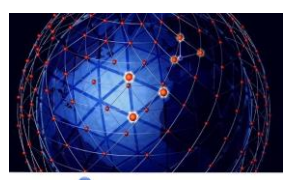

\section{INTRODUÇÃO}

O uso de substâncias psicoativas - as drogas $^{3}$ - tem se tornado cada vez mais frequente entre adolescentes, impactando no cotidiano escolar a medida que interfere nos processos de ensino-aprendizagem, na relação professor-aluno e no aumento dos índices de criminalidade entre os estudantes. Em pesquisa ${ }^{4}$ sobre a relação entre Escola e sujeitos autores de ato infracional em andamento no Programa de Pós-Graduação em Educação da Universidade de Brasília, tem se evidenciado que o uso de drogas costuma anteceder a infracionalidade e costuma iniciar-se com o pares na Escola. Apesar de numericamente inferior do que acreditam a maioria dos educadores que tende a ver o uso de drogas de forma generalizada na Escola, o tema merece a máxima atenção dos estudiosos das políticas sociais das áreas de educação, saúde e assistência social, pois, além de queixa comum a muitos educadores, o consumo de drogas nas Escolas brasileiras vem crescendo desde a primeira década deste século, de acordo com pesquisa da SENAD (2010). No Distrito Federal, pesquisa coordenada por Abramovay et al. (2009) revela índices acima da média nacional: na casa de $6 \%$.

Neste contexto, a Escola se apresenta como um fecundo espaço de enfrentamento às drogas, cuja maior capacidade de atuação é na prevenção, conforme previu o Plano Crack é

\footnotetext{
${ }^{3}$ Entende-se por drogas, em consonância com a Organização Mundial de Saúde, qualquer substância não produzida pelo organismo que tem a propriedade de atuar sobre um ou mais de seus sistemas, produzindo alterações nos mesmos. Mais especificamente, o artigo refere-se às drogas psicotrópicas ou psicoativas, que alteram as funções mentais, tais como álcool, tabaco, maconha, cocaína, crack, solventes voláteis, entre outros.

${ }^{4}$ Pesquisa de doutorado em andamento, ainda não publicada, realizada por Mauro Gleisson de Castro Evangelista, um dos autores deste artigo.
} 
Possível Vencer, em sintonia com a Política Nacional sobre Drogas (BRASIL, 2002). No Distrito Federal, o conjunto de orientações para o enfrentamento às drogas na Escola se materializou na Política sobre Drogas da Secretaria de Educação do Distrito Federal (SEDF), publicada por meio da Portaria 97, de 13 de junho de 2011. Trata-se de um documento legal que estrutura diretrizes e orientações para toda rede pública de ensino do Distrito Federal a desenvolver ações de enfrentamento às drogas, com eixo na prevenção.

Considerando o caráter inovador de uma iniciativa dessa natureza no âmbito das Escolas públicas, este artigo pretende relatar o processo de elaboração dessa política, descrevendo as ações previstas, realizadas, bem como os obstáculos para a sua efetiva implementação. Trata-se de um relato de experiências desenvolvido por meio de observação participante, já que atuamos como gestores e pesquisadores da área de educação. Situada no período de dezembro de 2011 a abril de 2014, a pesquisa teve como ponto forte a sistematização de avanços, dificuldades e desafios presentes no processo de implementação de uma política sobre drogas para as Escolas, porém com um olhar restrito a esfera da gestão, sem atingir o chão da Escola. Dessa forma, este artigo pretende ajudar a pensar caminhos para a efetiva implementação de uma política sobre drogas para as Escolas. Está estruturado em quatro seções, além desta introdução: o contexto institucional; a descrição da política; as ações realizadas; e a conclusão.

\section{CONTEXTO INSTITUCIONAL}

A Política sobre Drogas da Secretaria de Educação do Distrito Federal foi elaborada no âmbito da Coordenação de Educação em Direitos Humanos, inserida na Subsecretaria de Educação Básica, coração pedagógio da Secretaria de Educação do Distrito Federal - SEDF. Foi a principal ação da SEDF no interior do Comitê Distrital de Enfrentamento ao Crack e outras Drogas, criado por meio do Decreto 7.637 de 2011, no âmbito do Programa Crack é Possível Vencer. O referido programa foi uma iniciativa de caráter intersetorial, desenvolvida pelo Governo Federal, sob a coordenação do Ministério da Justiça, no período de 2011 a 2014. Em sintonia com a Política Nacional sobre Drogas, o programa era desenvolvido por meio de comitês intersetoriais criados nos estados, municípios e no Distrito Federal, com o intuito de implementar planos de enfrentamento às drogas pautadas nos eixo cuidado, 
autoridade e prevenção. No Distrito Federal, o Comitê era composto por 15 secretarias e a Companhia de Planejamento do Distrito Federal - CODEPLAN, responsáveis pela elaboração e implementação do Plano Distrital de Enfrentamento ao Crack e outras Drogas.

De acordo com o Plano Distrital de Enfrentamento ao Crack e outras Drogas, caberia às Escolas desenvolver ações preventivas de enfrentamento às drogas. Para isso, várias instituições adentravam nas Escolas na qualidade de entidades parceiras, dentre elas vale destacar a Polícia Militar, por meio do Programa Educacional de Resistência as Drogas e à Violência (PROERD) e a Secretaria de Justiça, Cidadania e Direitos Humanos, promovendo a vinda de palestrantes cuja metodologia, pautadas no amedrontamento, não correspondiam as expectativas da Política Nacional sobre Drogas.

Foram identificados na rede pública de ensino do Distrito Federal alguns equívocos que dificultavam as funções da Escola como agente de prevenção. Dentre eles, algumas compreensões errôneas do fenômeno das drogas muito coladas ao senso comum, tais quais: a crença de que a prevenção se daria pelo medo e por entidades parceiras sem a presença atuante dos profissionais da educação; palestras ou ações pontuais deslocadas do projeto político-pedagógico da Escola; punição e criminalização do usuário como alternativa para resolver o problema, quando de fato o acentua; a demonização da droga e o equívoco de acreditar que sozinha a Escola dará conta de enfrentar esse desafio sem mobilizar suas redes internas e externas.

Com base nesse diagnóstico, foi possível identificar a necessidade de um documento orientador que ajudasse as diversas instâncias da SEDF e os profissionais da educação a repensarem suas intervenções em relação às drogas na Escola, o que resultou no lançamento da Política sobre Drogas da SEDF, publicada no Diário Oficial do Distrito Federal de 29 de junho de 2012, por meio da Portaria n ${ }^{\circ}$ 97, de 13 de junho de 2012.

\section{A POLITICA SOBRE DROGAS DA SEDF}

A publicação da Política Sobre Drogas da Secretaria de Educação do Distrito Federal SEDF foi uma iniciativa pioneira do Distrito Federal que visava orientar os profissionais da educação no desenvolvimento de ações de enfrentamento às drogas, de modo que todas as 
instâncias da rede pública de ensino tivesse clareza de seus papéis no enfrentamento ao uso de drogas. Embora muitos profissionais já desenvolvessem trabalhos de prevenção do uso de drogas nas Escolas, foi a primeira vez que a SEDF propôs um plano de ação articulado para coordenar as ações no âmbito da rede de pública de ensino como uma ação estratégica do Plano Distrital de Enfrentamento ao Crack e outras Drogas.

A iniciativa, realizada com o apoio do Programa de Estudos e Atenção às Dependências Químicas - PRODEQUI da Universidade de Brasília - UnB, partia de pesquisas acadêmicas que vinham revelando que o uso de drogas, especialmente na adolescência, está associado à construção da identidade e da autoestima, decorrentes de processos de interação que envolvem as relações familiares, Escolares e socioculturais. Como a Escola é um espaço de interação capaz de oportunizar novas formas de relações sociais e novas formas de se relacionar, além de ser um dos mais significativos elementos para a (re)construção da autoimagem e autoestima, ela desempenha um papel fundamental na prevenção do uso de drogas, pois é capaz de propiciar condições para a reflexão crítica, a autoestima e a descoberta de prazeres que deem um novo sentido à vida dos estudantes (BRASIL, 2012).

Já previa o Plano Crack, é Possível Vencer que, no enfrentamento às drogas, caberia às Escolas atuar prioritariamente no desenvolvimento de ações preventivas nos campos da prevenção primária, secundária ou terciária, sendo esta última destinada àqueles que se encontram em estágio de dependência química. Neste caso, a Escola deveria identificar, acolher, orientar e encaminhar para a Rede de Proteção Social, especialmente para as equipes especializadas em atendimento de crianças e adolescentes que funcionam nas Unidades Básicas de Saúde mais próximas da Unidade Escolar ou, quando maiores de 18 anos, para os Centros de Atenção Psicossocial em Álcool e outras Drogas - CAPS AD.

Alinhadas às políticas intersetoriais de enfrentamento às drogas, as ações preventivas deveriam ser:

- Pautadas em princípios éticos e na pluralidade cultural, orientando-se para a promoção de valores voltados à saúde física e mental, individual e coletiva, ao bem-estar, à integração socioeconômica e a valorização das relações familiares, 


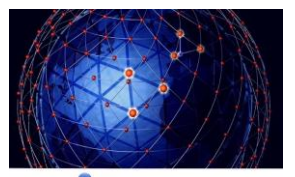

considerando seus diferentes arranjos;

- Planejadas e direcionadas ao desenvolvimento das potencialidades do ser humano; ao incentivo à educação para uma vida saudável; ao acesso aos bens culturais, incluindo a prática de esportes, cultura, lazer; à socialização do conhecimento sobre drogas, com embasamento científico; ao fomento da efetiva participação juvenil, da família, da Escola e da sociedade na multiplicação dessas ações;

- Promovidas no sentido de estimular e apoiar a formação continuada, o trabalho interdisciplinar e multiprofissional com a participação de todos os atores da comunidade Escolar, no intuito articular, fortalecer e ampliar as redes sociais de prevenção às drogas;

- Direcionadas ao desenvolvimento do ser humano em sua integralidade, a partir da perspectiva da Educação Integral e da Saúde Integral, pautadas no efetivo exercício da cidadania, no respeito à dignidade da pessoa humana e na melhoria da qualidade de vida.

Por este viés, a Política tentava ir na contramão do imaginário de grande parte da população que associa os usuários de drogas à criminalidade e à delinquência. Esta percepção, difundida de forma distorcida pela mídia, gera medo e leva, muitas vezes, a adoção de posturas, exclusivamente, coercitivas, policialescas e excludentes, as quais, a experiência e os estudos acadêmicos têm demonstrado que podem acabar por aumentar o consumo, ao invés de reduzir. Partia-se do entendimento as drogas sempre estiveram presentes na história da humanidade, com os mais diversos sentidos nas diferentes culturas.

Atualmente, tem estado muito presente nos processos de busca de prazer, transgressão e experimentação, típicos da adolescência. O problema efetivamente começa quando o uso ultrapassa a fase experimental para tornar-se abusivo, trazendo dependência e disfunções para a vida do adolescente. Para além das implicações negativas na saúde do estudante, o uso de drogas entre adolescentes traz outros problemas para o ambiente Escolar: a proximidade com o tráfico, a violência e representações sociais discriminatórias que acabam por estigmatizar o usuário, associando-o à criminalidade, à dependência química e à deliquência antes mesmo de 


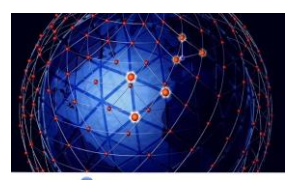

conhecê-lo. Tais estigmas, associados à pedagogia do medo e à repressão, têm contribuído mais para o afastamento dos adolescentes da Escola do que das drogas.

Alinhada aos grandes pesquisadores da temática no Brasil, a Política sobre Drogas da SEDF compreendia o uso de drogas como sintoma de vulnerabilidades pessoais e ou sociais. Logo, no exercício de seu papel reconhecidamente preventivo, buscou-se orientar as Escolas no desenvolvimento de ações que contribuíssem para a redução dos fatores de risco que levam ao uso de drogas e para o fortalecimento dos fatores de proteção que afastam os estudantes do mundo das drogas. Entre estes fatores, concernentes ao ambiente Escolar, valem destacar:

I - Fatores de riscos nas Escolas:

a) Quando o aluno não se sente devidamente acolhido no ambiente Escolar, seja pelos pares e ou pela organização Escolar;

b) sentimento de menor valia enquanto aluno e consequentemente, enquanto pessoa;

c) incoerência na construção e efetivação das normas: ausência ou fragilidade das normas Escolares, falta de clareza das normas, invisibilidade das normas, caráter condicionante das normas, (hetero)nomia das normas, viés retributivo da justiça no ambiente Escolar;

d) ausência de referências sólidas de autoridade que deem suporte e continência às angústias próprias da adolescência;

e) ausência de relações de cooperação na família com desdobramentos para a Unidade Educacional;

f) ausência de relações de cooperação entre família e a Unidade Educacional;

g) distanciamento afetivo na relação professor-aluno;

h) frustração e pressão diante das experiências de (não)aprendizagem; 
i) desmotivação e desengajamento em relação às atividades Escolares;

j) desempoderamento de alunos no espaço Escolar;

k) ausência de espaços de expressão dos conteúdos não ou mal elaborados pelos estudantes;

1) ausência de espaços para o esporte, a arte e o lazer;

m)momento no qual o aluno encontra-se em situação de risco e ou vulnerabilidade;

n) o fenômeno da adolescência sem o devido amparo e suporte das instituições sociais;

o) riscos e vulnerabilidades cujo enfrentamento são de política públicas pertencentes a outras instâncias do Estado, quando a Escola não se encontra articulada com essa rede;

p) fragilidade dos mediadores culturais (padrões estéticos, lugar dos adultos na relação intergeracional, valores apregoados pelos interesses hegemônicos);

q) anacronismo da Escola para com as novas configurações da juventude;

r) mal-estares pós-modernos;

s) conflitos desqualificantes da autoimagem no ambiente Escolar;

t) ausência de espaços de construção coletiva, de autoria, de autorização: de democracia;

u) proximidade da rede de distribuição de drogas; e

v) relação com colegas usuários dentro da Unidade Educacional.

II - Fatores de proteção nas Escolas: 


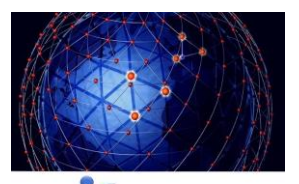

a) ajudar o aluno a sentir-se pertencente à comunidade Escolar;

b) ajudar o estudante a encontrar o seu valor enquanto pessoa e ou enquanto aluno;

c) coerência na construção e efetivação das normas: presença de normas claras, visíveis, conscientizantes e coerente para todos que dela compartilham, (auto)nomia, concepção restaurativa da justiça no ambiente Escolar;

d) presença de referências sólidas de autoridade que deem suporte e continência às angústias próprias da adolescência;

e) ofertar suportes e continências às carências e conflitos oriundas do ambiente familiar;

f) relação de cooperação entre a família e Unidade Educacional;

g) relação de respeito e consideração (do outro) entre educador e aluno;

h e i) estímulo e motivação para o êxito Escolar, o que passa por pensar projetos pedagógicos interventivos a partir da realidade do estudante;

j) implementação de dispositivos que fomentem a participação dos jovens no ambiente Escolar;

k) Garantia de espaços para as múltiplas formas de expressão dos alunos;

1) Garantia de espaços para o esporte, a arte e lazer para os alunos;

m) Atenção e cuidado especial e especializado para as pessoas em situação risco e ou vulnerabilidade;

n) Atenção e cuidado especial com o fenômeno da adolescência;

o) Acionamento dos outros órgãos da rede de proteção social para os casos de crianças e adolescentes em situações de risco e ou vulnerabilidade;

p) espaço de reflexão e crítica junto aos adolescentes sobre os mediadores 


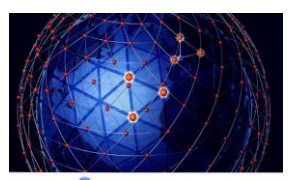

culturais hegemônicos;

q) reinvenção da Escola para dar conta das novas realidades colocadas pela pósmodernidade;

r) espaço para a reflexão, crítica e elaboração de mal-estares próprios da atual conjuntura;

s) espaços para a reflexão, crítica, mediação e reinvenção das relações no espaço Escolar;

t) garantia de espaços de construção coletiva, de autoria, de autorização: de democracia;

u) realização de programas, projetos e ações de prevenção do uso de drogas; mobilização e conscientização sobre a realidade de consumo; ambiente seguro e protetor; oportunidades concretas para a inserção profissional do adolescente que se encontre em idade para o trabalho.

Assim, o enfrentamento às drogas na Escola seria possível por meio de ações pedagógicas que possibilitassem a autonomia, o protagonismo, o acolhimento e a melhoria da autoestima dos estudantes, de modo planejado, processual e inserido no projeto políticopedagógico. Entendia-se como necessário que os educadores contemplassem a prevenção do uso de drogas em seus planejamentos pedagógicos, de forma transversal, a partir da educação e da saúde integral que desenvolve o ser humano em suas múltiplas potencialidades.

A tentativa de implementação de uma política pública social sobre drogas específica para a área de educação buscou efetivamente compartilhar responsabilidades no enfrentamento às drogas, orientando as ações de cada setor e ator que atuasse direta ou indiretamente no ambiente Escolar. Segundo a referida Política, caberia ao:

\section{COORDENADOR INTERMEDIÁRIO NAS REGIONAIS DE ENSINO:}

- Sensibilizar o Gerente e demais coordenadores intermediários sobre a 


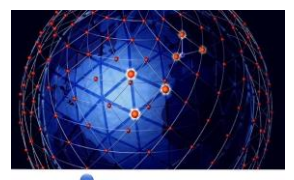

importância de ações de enfrentamento às drogas dentro de cada etapa e modalidade de ensino na Escola;

- Provocar ações que aproximem ou reforcem a discussão nas Escolas sobre a as ações de prevenção do uso de drogas;

- Provocar a Escola no intuito de que promovam estratégias de orientação e sensibilização das famílias sobre a importância do diálogo e do acolhimento no enfrentamento às drogas;

- Fomentar a inserção de projetos e ações de enfrentamento às drogas nos Projetos Políticos Pedagógicos (PPP) das Escolas, na perspectiva da educação em direitos humanos.

- Articular as demandas da Rede de Proteção Social e da Escola no que se refere ao enfrentamento ao uso de drogas;

- Distribuir folhetos informativos e materiais educativos referentes ao enfrentamento às drogas;

- Realizar ações que incentivem a conscientização dos profissionais da educação para a importância da Escola na redução dos fatores de risco e no fortalecimento dos fatores de proteção que afastam os estudantes de ambientes não saudáveis que propiciem o uso de drogas;

- Divulgar e realizar os cursos de formação continuada sobre enfrentamento às drogas;

- Orientar os profissionais da educação sobre como proceder nos diversos tipos de casos de envolvimento com drogas na Escola;

- Divulgar, apoiar e acompanhar a execução da Política sobre Drogas da SEDF, no âmbito das Escolas que lhe são vinculadas;

- Divulgar, apoiar e demandar a realização os cursos de formação continuada 


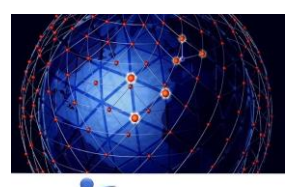

sobre a temática das drogas;

- Apoiar e orientar as Escolas no desenvolvimento de programas, projetos e ações de enfrentamento às drogas;

- Realizar a articulação entre as demandas das Escolas e da COEDH, no que tange a temática das drogas.

\section{Diretor:}

- Potencializar os anseios da comunidade Escolar para que se tornem ações efetivas de prevenção do uso de drogas;

- Deliberar junto ao Conselho Escolar ações sobre prevenção ao uso de drogas;

- Distribuir funções para a elaboração e implementação de projetos de prevenção ao uso drogas nas Escolas;

- Fortalecer a participação da Unidade de Ensino na Rede de Proteção Social de sua cidade e acompanhar a execução do projeto.

\section{Supervisor Pedagógico (a):}

- Articular junto à Gerência Regional de Educação Básica, à Coordenação Regional de Ensino e à Rede Externa, para a implementação de projeto de prevenção do uso de drogas nas Escolas;

- Coordenar a execução do planejamento da equipe gestora;

- Articular a aplicação do projeto entre professores e coordenadores;

- Viabilizar as demandas surgidas da coordenação pedagógica e articular a comunicação entre os coordenadores e a equipe gestora da Escola.

\section{Coordenador Pedagógico das Unidades de Ensino:}

- Coordenar as ações, projetos e planejamentos sobre drogas junto ao coletivo de 


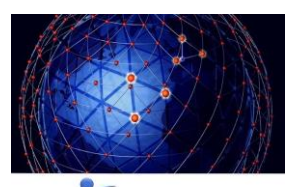

professores;

- Articular a comunicação entre os professores e a equipe gestora no que tange à temática das drogas;

- Coordenar as ações e projetos sobre drogas junto ao coletivo de professores;

- Propor, discutir e viabilizar a execução do projeto de prevenção do uso de drogas nas Escolas.

\section{Orientadores Educacionais das Unidades de Ensino:}

- Participar ativamente da elaboração coletiva de projetos e ações que visem a prevenção do uso de drogas junto à equipe gestora e à coordenação pedagógica;

- Acompanhar a execução dos projetos de prevenção ao uso de drogas junto aos alunos;

- Levar demandas à equipe diretiva e professores;

- Estar atento a fatores de risco;

- Fomentar a implementação de fatores de proteção, para além das medidas coercitivas;

- Encaminhar à rede de proteção social, em conjunto com a equipe gestora, casos de vulnerabilidade, de suspeita ou comprovado uso indevido de drogas.

\section{Professores em regência:}

- Realizar cursos de formação continuada sobre a temática das drogas;

- Inserir a questão das drogas como tema transversal em sua disciplina;

- Estar sempre atento aos fatores de risco e a suspeita ou comprovação do uso de drogas entre os estudantes;

- Sinalizar à equipe gestora quadros de vulnerabilidade, fatores de risco, suspeita 


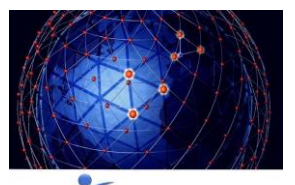

ou comprovação de uso indevido de drogas;

- Fomentar a implementação de fatores de proteção, para além das medidas coercitivas;

- Participar da elaboração e da execução de programas, projetos e ações junto aos estudantes.

Conforme foi possível perceber acima, a Política sobre Drogas da SEDF buscou responsabilizar as diversas instâncias e profissionais da educação no enfrentamento às drogas. Apesar da dificuldade de avaliar sistematicamente o impacto da referida Política no chão da Escola, foi possível evidenciar ao longo da pesquisa que, mesmo com a ampla divulgação junto às coordenações regionais de ensino, esta não chegou a ser amplamente (re) conhecida pelos educadores nas Escolas. Tanto os coordenadores intermediários de direitos humanos como os educadores presentes nas Escolas expressaram dificuldade para se reunir e sistematizar um projeto preventivo. Segundo eles, em virtude do excesso de demandas consideradas mais urgentes pelas gestões central e intermediárias da Secretaria, como a resolução dos casos de violência Escolar, os demais projetos e programas enviados pelo Ministério da Educação - MEC para serem implementados, a discussão sobre o currículo que estava sendo reformulado à época, etc.

\section{AS AÇÕES REALIZADAS}

Com o intuito de divulgar a referida Política, foi realizada uma cerimônia de lançamento em 18 de junho de 2012, que contou com a palestra "O papel da Escola na prevenção do uso de drogas: desafios, possibilidade e construções metodológicas para a prevenção pelos educadores”, proferida pela Profa. Dra. Maria Fátima Olivier Sudbrack, Coordenadora do PRODEQUI da UnB.

Além disso, considerando o caráter estratégico da formação para os profissionais da educação, foi realizada ampla divulgação do "Curso de Prevenção do Uso de Drogas para Educadores de Escolas Públicas", realizado por meio de uma parceria entre a Secretaria Nacional de Políticas sobre Drogas - SENAD, o Ministério da Educação - MEC e o 
PRODEQUI da UnB. O curso contou com 1.700 (um mil e setecentos) inscritos da rede pública de ensino do DF, entre professores, coordenadores pedagógicos, gestores e técnicos educacionais.

No primeiro semestre letivo de 2013, a SEDF realizou uma parceria com o PRODEQUI-UnB, por meio do curso "O lugar da Escola na prevenção ao uso indevido de drogas: desafios, possibilidades e metodologias para a prevenção pelos educadores”, com o objetivo de formar servidores para atuarem no processo de implementação e acompanhamento da Política sobre Drogas da SEDF. O curso teve como público alvo os coordenadores intermediários de educação em direitos humanos e de educação em diversidade $^{5}$, representantes da Subsecretaria de Educação Básica ${ }^{6}$ - SUBEB, representantes do Programa Saúde na Escola - PSE, além de representantes da Secretaria de Desenvolvimento Social e Transferência de Renda - SEDEST, que atuam com projetos educacionais dentro dos equipamentos da SEDEST. Esta iniciativa resultou no Pólo de Pesquisa DF, no âmbito do PRODEQUI da UnB.

Com o intuito de comprometer os educadores no desenvolvimento de ações de prevenção ao uso de drogas, anteriormente relegada à entidades parceiras que não raras vezes realizavam atividades pontuais, de caráter repressivos e amedrontadores desconectadas de todas as legislações vigentes, buscamos - enquanto setor da SEDF responsável pela temática abrir campos de diálogos com as entidades parceiras. Uma das principais era o Programa de Educacional de Resistência às Drogas e à Violência - PROERD, um programa da Polícia Militar do DF por meio do qual policiais do Programa oferecem um conjunto de oficinas para alunos do $5^{\circ}$ ano do Ensino Fundamental.

Foi solicitado a esses e outros parceiros que não entrassem em Escolas sem que as mesmas elaborassem um plano de ação conjunto com ações previstas para serem realizadas antes, durante e depois da entrada do policial proerdiano na Escola. Tal plano de ação deveria ser encaminhado à Coordenação de Educação em Direitos Humanos e acompanhado pelo

\footnotetext{
${ }^{5}$ Representantes nas cidades de Brasília das ações junto à Educação em Direitos Humanos, especialmente da Escolarização dos sujeitos em peculiar estado de risco e ou vulnerabilidade.

${ }^{6}$ Representantes da gestão pedagógica central.
} 
coordenador intermediário de direitos humanos, responsável por acompanhar os projetos pedagógicos realizados nas Escolas. Foram recebidos à época aproximadamente 50 projetos, mas nem todas foram visitadas pela entidade parceira, em virtude da falta de proximidade da residência do palestrante. A experiência levou a refletir sobre a dificuldade de desenvolver ações intersetoriais no âmbito da rede de proteção, visto que as relações ainda estão permeadas pela lógica do favoritismo que historicamente estiveram presentes na sociedade brasileira.

\section{CONCLUSÃO}

Este trabalho, realizado por meio de observação participante, teve como objetivo fazer um relato de experiência sobre o processo de implementação de uma política sobre drogas para a Escola. Restrito a perspectiva da gestão, não foi foco deste trabalho avaliar o impacto desta política na Escola. O Pólo de Pesquisa do PRODEQUI identificou a existência de projetos de prevenção do uso de drogas, realizados no âmbito do Curso de Prevenção do Uso de Drogas para Educadores de Escolas Públicas. Tais projetos, embora possam ter sido resultados do processo de divulgação do curso para a implementação desta Política, constituem iniciativas pontuais realizadas por grupos de professores nas Escolas, o que não necessariamente representa indícios de enraizamento da referida política na rede pública de ensino do DF.

A implementação de uma política pública sobre drogas não é simples, pois envolve a discussão de uma série de questões de caráter moral, cultural, religioso, individual e coletivo que dividem diversos setores e grupos sociais. Observou-se a necessidade de uma priorização deste debate no âmbito das gestões central e intermediárias da SEDF, de modo que toda a rede pública de ensino se mobilizasse para o tema, sensibilizando os profissionais da educação para uma postura mais acolhedora para com os estudantes tornando a Escola um espaço de efetiva proteção para com seus estudantes. $\mathrm{O}$ desafio consiste, portanto, em sensibilizar os profissionais da educação para a importância da efetivação dessa Política como forma de contribuir para o enfrentamento às drogas e melhoria da convivência na Escola.

Conforme entende Pereira (2008), as políticas públicas são resultado da correlação de 


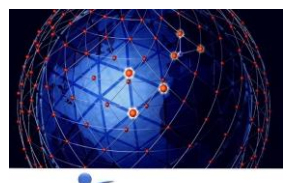

forças presentes na sociedade, atendendo a interesses de diferenciados grupos sociais, a depender da sua capacidade de articulação junto à agenda pública. Diferentemente daquelas perspectivas comuns no serviço público que sonham em transformar política de governo em políticas de Estado, para Pereira (2008) o que garante a permanência de uma política social é o seu caráter público dado por meio da pressão de diversos setores sociais e o controle democrático da população.

A Política sobre Drogas da SEDF nasceu dentro de uma Coordenação de Educação em Direitos Humanos, que tinha como responsabilidade representar a SEDF no Conselho de Política sobre Drogas do Distrito Federal e no Comitê Distrital de Enfrentamento ao Crack e outras Drogas. Em virtude das pressões do governo federal no âmbito do Programa Crack é Possível Vencer, o governador do Distrito Federal solicitava às secretárias de estado que compunham o Comitê Distrital, relatórios trimestrais com as ações de enfrentamento às drogas realizadas no período. Esta necessidade de prestação de contas facilitou os trâmites para a publicação da portaria. Entretanto, não foi o suficiente para convertê-la em política pública, no sentido proposto por Pereira (2008), tornando-a, até o presente momento da história, letra morta, apenas mais uma lei para os ingleses, porém, de suma importância para repensarmos os caminhos trilhados pela Escola frente ao fenômeno das drogas.

\section{REFERÊNCIAS}

ABRAMOVAY, Mirian (coord.) et al. Revelando tramas, descobrindo segredos: violência e convivência nas Escolas. Brasília: RITLA/SEEDF, 2009.

APPLE, M. Educação e Poder. Porto Alegre, Artes Médicas, 1989.

BRASIL, Presidência da República. Decreto n 4.345, de 26 de agosto de 2002.

BRASIL - Secretaria Nacional de Políticas sobre Drogas - SENAD. Curso de prevenção do uso de drogas para educadores de Escolas públicas. $5^{\mathrm{a}}$ ed. atualizada. Brasília: SENAD; MEC, 2012.

PEREIRA, P. Discussões conceituais sobre política social como política pública e direito de cidadania. In: BOSCHETTI et al. (org.) Política Social no Capitalismo: Tendências Contemporâneas. São Paulo, Ed. Cortez, 2008.

RESES, E. S. Singularidade da Profissão de professor e Proletarização do Trabalho Docente 
na Educação Básica. In: Revista Ser Social. Brasília, v.14, n 31, 2012.

SENAD. VI Levantamento Nacional sobre o Consumo de Drogas Psicotrópicas entre Estudantes do Ensino Fundamental e Médio das Redes Pública e Privada de Ensino nas 27 Capitais Brasileiras - 2010/ E. A. Carlini (supervisão) [et. al.], -- São Paulo: CEBRID Centro Brasileiro de Informações sobre Drogas Psicotrópicas: UNIFESP - Universidade Federal de São Paulo, 2010. 